\title{
La méthode Hollande
}

\author{
François Hollande, the new French president, has an opportunity to correct and consolidate five years of \\ frantic research reforms under Nicolas Sarkozy.
}

The victory of François Hollande of the Socialist Party over Nicolas Sarkozy of the Union for a Popular Movement party in France's presidential election in May 2012 owed much to his promise to be a 'normal' president. Hollande turned his modest and unassuming nature to his advantage against Sarkozy, who was widely perceived as often being brash, authoritarian and divisive. Many French scientists too, will be glad to see the back of a president whose methods and rhetoric often alienated him from the research community - not least by his infamous portrayal of them as a bunch of layabouts (Nature 457, 636; 2009). Hollande has pledged to govern more consensually, and la méthode Hollande, may be just what French research needs after being buffeted by five years of non-stop research reforms under Sarkozy, which were often imposed by the government with little consultation.

Historically, science spending has fallen under conservative governments, and risen under Socialist ones, but to his credit Sarkozy bucked that trend (from $2.1 \%$ of GDP in 2007 to $2.3 \%$ of GDP in 2011), making research a priority and one of the few public sectors to be spared cuts during his term. Many researchers also give Sarkozy credit for - as predicted (Nature Mater. 6, 393; 2007) - tackling long-overdue research reforms, such as giving the universities independence from the state, shifting research funding away from rolling lab-funding to competitive grant proposals, and concentrating funding to create universities and centres of excellence equipped to compete internationally. But many also take issue with how the often rushed reforms have been implemented, with a proliferation of new schemes and organizations lacking overall coherence, in particular with existing structures, while researchers complain of a concomitant increase in duplicated efforts, bureaucratic complexity and growing inégalités in the distribution of research funding.

Sarkozy has dismissed such problems as temporary, likening the restructuring of French research and higher education to a major building site, arguing that as the scaffolding and tarpaulins are gradually removed, a new and better research edifice

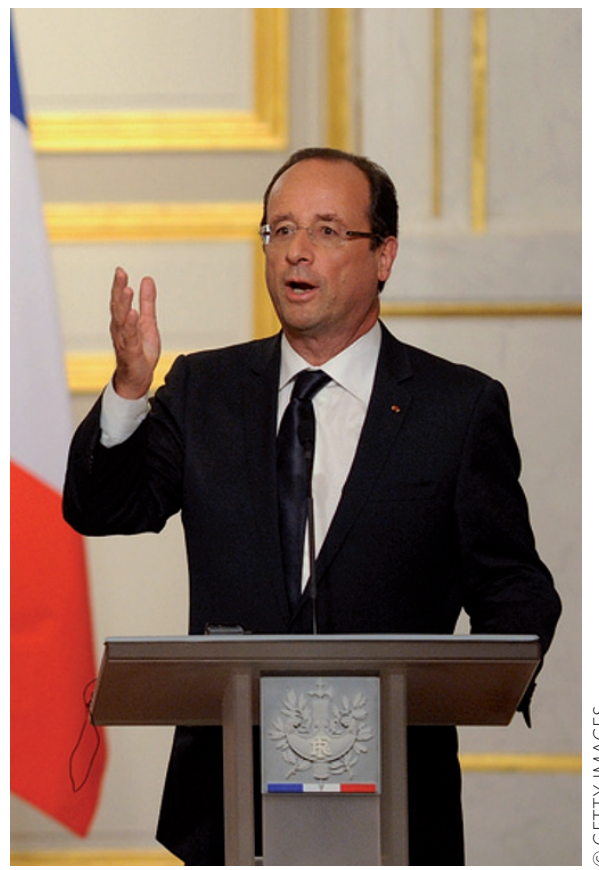

powers and commitments that autonomy has entailed, and several universities are as a result struggling with budget deficits. Meanwhile billions of euros of endowments to promote excellence have largely benefited a handful of universities, raising concerns of unnecessarily destructive competition and geographical disparities in higher education and research.

The French National Research Agency (ANR), which was created in 2005 and now has an annual budget of around $€ 1$ billion, was Sarkozy's main tool for shifting research funding in France from a model where the research organizations largely allocated rolling funding to labs, to one where it is increasingly allocated on the basis of competitive grant proposals. The ANR has helped many young researchers get independent funding, but many scientists complain that the agency is opaque and bureaucratic, and its selection of research directions is too top-down. In France's complex research system, most labs belong to one or more research organizations and a university, but the main research organizations, such as the Centre National de la Recherche Scientifique (CNRS), have been sidelined, and many good groups at the research organizations have seen their lab funding slashed.

Hollande has promised that research and higher education will be government and budgetary priorities. Public spending is, however, under intense pressure because of the bank and euro crises and the new government's financial margin for manoeuvre will be limited - and seems to exclude any large increases in research spending - and could be restricted further by any worsening of the crises.

The Hollande government, which enjoys wide support among researchers, has an opportunity to take the best of the Sarkozy reforms. Its own detailed plans for research remain vague, but should become clearer during and after the planned consultation. One risk is compromise and inaction, and also the extent to which the government heeds the anachronistic views of the more reactionary elements in parts of both the Socialist Party and the research community. Researchers must see to it that sensible voices prevail. 